\title{
LAS FALACIAS DISCURSIVAS EN TORNO A LA IDEOLOGÍA DE GÉNERO
}

Maricel Mena-López* y Fidel Mauricio Ramírez Aristizábal *:

\section{Resumen}

Los discursos en torno a la llamada Ideología de Género han mutado en cada región de América Latina y han hecho metástasis a distintos niveles sociales. En Colombia, la estrategia ha estado mediada por la desinformación y por la falta de un movimiento social fuerte que le haga frente a los argumentos que encierra el discurso cada vez más confuso; razón por la cual, en el presente artículo se presenta la evolución del concepto y su impacto en los fundamentalismos religiosos en Colombia y Latinoamérica hasta develar las principales falacias que en torno a estos discursos se puedan identificar, con el fin de contribuir, desde la academia, al debate de lo que podría llamarse una de las estrategias más fuertes en los últimos años para impedir el avance y retroceder en materia de derechos de mujeres y personas Gais, Lesbianas, Bisexuales y Transexuales.

Palabras clave: Género, fundamentalismos religiosos, falacias discursivas, movilización social, ideología de género.

\section{Resumo}

As falácias discursivas em torno da ideologia de género

A discussão em torno da chamada ideologia de género tem sofrido alterações em cada região da América Latina e tem metastizado nos diferentes níveis sociais. Na Colômbia, a estratégia tem estado mediada pela desinformação e pela falta de um movimento social forte que faça frente aos argumentos em torno de um discurso cada vez mais confuso; por este motivo, no presente artigo, apresenta-se a evolução do conceito e seu impacto nos fundamentalismos religiosos colombianos e latino-americanos, assinalando as principais falácias discursivas que se podem evidenciar em torno desse discurso. Pretende-se assim contribuir para o debate do que poderia ser chamado de uma das estratégias mais fortes, nos últimos anos, para impedir o avanço e retirar direitos às mulheres e aos Gays, Lésbicas, Bissexuais e Transexuais.

Palavras-chave: Feminismo e género, fundamentalismos religiosos, falácias discursivas, mobilização social, ideologia de género.

\section{Abstract}

Discursive fallacies regarding gender ideology

The discourses around so-called Gender Ideology have changed in each region of Latin America and have metastasized to different social levels. In Colombia, the strategy has been

\footnotetext{
* Universidad Santo Tomás. 110231 Bogotá. Colombia.

Dirección postal: Universidad Santo Tomás, Kra. 9 51-11, 110231 Bogotá, Colombia.

Correo electrónico: maricelmena@usantotomas.edu.co

** Universidad Santo Tomás. 110231 Bogotá. Colombia.

Correo electrónico: fidelramirez@usantotomas.edu.co
} 
influenced by misinformation and the lack of a strong social movement that confronts the arguments contained in an increasingly confusing discourse. This is why, in this article, the evolution of the concept and its impact on Colombian and Latin American religious fundamentalisms is presented with the aim of revealing the main discursive fallacies that surround this discourse. The ultimate objective is to contribute, from within the academy, to the debate of what could be called one of the most forceful strategies, in recent years, to cut off progress and turn back on the rights of women and Gays, Lesbians, Bisexuals and Transsexuals.

Keywords: Feminism and gender, religious fundamentalisms, discursive fallacies, social mobilization, gender ideology.

\section{Introducción}

En Colombia, desde julio de 2016, se activaron las alarmas entre los sectores más conservadores de la política y la religión nacional en torno a la llamada ideología de género que, según ellos, era promovida por un lobby gay, ${ }^{1}$ para ejercer influencia en el proceso de revisión de manuales de convivencia de las instituciones educativas de básica y media en el territorio nacional, ${ }^{2}$ así como en los acuerdos que se pactaron en la Habana, entre el gobierno nacional y las Fuerzas Armadas Revolucionarias de Colombia (FARC) para darle fin al conflicto armado que se ha prolongado por más de cinco décadas en el territorio nacional, dejando más de 5 millones de personas desplazadas y 220 mil muertes (Human Rights Watch 2014).

Ante las aparentes amenazas de la llamada ideología de género, se creó una coalición entre diversas organizaciones y líderes religiosos, con cierto nivel de participación política, para obligar a que el Ministerio de Educación Nacional detuviera el proceso de revisión de los manuales de convivencia y que se renegociara el acuerdo de paz para erradicar cualquier expresión del enfoque de género que había sido una conquista de las organizaciones que trabajan por la defensa de los Derechos Humanaos de mujeres y personas pertenecientes a los sectores LGBTI.

En ese contexto, se exacerbaron los fundamentalismos religiosos (Wirherup $2009,11),{ }^{3}$ que, unidos a los sectores de extrema derecha en el país, reactivaron el debate en torno a los avances en materia de derechos sexuales y reproductivos de mujeres y personas con orientaciones sexuales e identidades de género diversas y

1 El término se acuñó a finales de la década de 1990 para referirse de manera peyorativa a la participación de gais y lesbianas en espacios políticos de toma de decisión sobre derechos civiles de personas con orientaciones e identidades de género no heterosexuales o binarias.

2 La revisión de los Manuales de Convivencia fue ordenada por la Corte Constitucional de Colombia (2015) en la Sentencia T-478/15, de 2015, con el fin de evitar actos de discriminación y violencia contra estudiantes sexualmente diversos que tengan desenlaces lamentables como el suicidio del joven Sergio Urrego, que dio origen a esta sentencia.

Cuando se habla de fundamentalismo, inmediatamente lo identificamos como un movimiento ultraconservador, pero en realidad existen diversas formas de fundamentalismos, incluso en los sectores llamados liberales se evidencian fundamentalismos tan rígidos e inflexibles como los conservadores. 
llevando a cabo una verdadera cruzada a favor del modelo hegemónico de familia patriarcal y heterosexual.

En debates políticos, se usó la Biblia para sustentar y fundamentar comportamientos homofóbicos, para rechazar cualquier tipo de relación «antinatural», generándose de esta manera lo que podríamos llamar una guerra santa en contra de aquellas personas con expresiones y prácticas consideradas como depravación debido a una hermenéutica bíblica reduccionista, que desconoce importantes trabajos que han cuestionado la univocidad con que se han entendido algunos pasajes bíblicos que se emplean para condenar las prácticas homosexuales o impedir la emancipación de la mujer (Lings 2011, 28).

Por esto, entre otras cosas, es que las teólogas feministas de hoy nos sentimos interpeladas principalmente por el uso de la categoría género en el contexto religioso actual. Esto en vista del rechazo y polarización política y religiosa del término, en sectores católicos y evangélicos, que ven al género como una ideología que pone en peligro la constitución de la estructura binaria, que ha caracterizado a la humanidad durante siglos. De esta forma se desconoce la manera asimétrica en que se establecen las relaciones entre hombres y mujeres, en función de las características biológicas pensadas como una naturaleza fija (Scott 1990, 23).

Por todo lo dicho, la pregunta que nos surge desde la actual coyuntura colombiana es ¿cómo construir paz, si las iglesias cristianas, como principales garantes de la misma, están promoviendo una verdadera guerra discursiva? Esto a partir de lo ocurrido en las recientes manifestaciones en contra de la visita de Judith Butler ${ }^{4}$ a Brasil en el 2017 en relación a su aporte en entorno a una des-configuración de los conceptos tradicionales del género, la cual se ha convertido en una bandera para los movimientos LGBTI que asumen las identidades en tránsito como apuesta política de inclusión social y religiosa, como lo advierte Castellanos citando a Butler.

Judith Butler plantea la posibilidad de abandonar la diferenciación entre «sexo y género» $[\ldots] \mathrm{o}$, al menos, de invertir la primacía atribuida al sexo por encima del género: no es el sexo la base biológica natural, fundamental, e invariable sobre la cual cada cultura construye sus concepciones, sus roles y estilos de género, sino que es el género cultural el que nos permite construir nuestras ideas sobre la sexualidad, nuestras maneras de vivir nuestro cuerpo, incluyendo la genitalidad, y nuestras formas de relacionarnos física y emocionalmente (Castellanos 2017).

Pretendemos en estas breves páginas interpelar el uso y el abuso del discurso eclesial en contra del papel de las mujeres y de los grupos LGBTI en la actual

Judith Butler es una filósofa norteamericana cuyos aportes al feminismo han generado controversias especialmente en la formulación teórica de la Teoría Queer. Su obra más controvertida con relación a las libertades sexuales es El género en disputa. El feminismo y la subversión de la identidad. Barcelona: Paidós, 2006. 
coyuntura colombiana. No sin antes situar esta categoría de género como herramienta analítica dentro del feminismo crítico, en el marco de las luchas sociales de reivindicación por los derechos civiles de las mujeres, del movimiento negro, de los trabajadores, en fin, de estos y otros movimientos que problematizan las asimetrías sociales. Estos movimientos cuestionan las categorías fundamentales de ciencia, teorías y metodologías occidentales (Ramírez y Mena-López 2014, 104-122). Así pues:

La categoría género es una dimensión fundamental en la construcción de las jerarquías sociales. Por lo tanto, es importante para develar no sólo las asimetrías de sexo-género, sino también las asimetrías sociales, de allí que casi siempre se estudia teniendo en cuenta las variables raza/etnia y clase (Aguilar 2007, 83-88).

Esta categoría dentro del movimiento feminista se propone lidiar con las diferencias y situarlas en contexto. Es usada para interpelar las relaciones jerarquizadas entre hombres y mujeres. El género designa los significados simbólicos asociados al sexo, que eran tratados como «naturales», y que justificaban la subordinación de las mujeres como algo natural.

Teniendo en cuenta lo anterior, asumimos el término feminista como una línea de pensamiento ampliamente reconocida en el mundo académico y también por el mundo eclesial, en especial por su reconocimiento en los estudios bíblicos. La Pontificia Comisión Bíblica (2005), al abordar, en 1993, el tema de la lectura contextual de la Biblia, en su texto «La interpretación de la Biblia en la Iglesia», reconoce el valor y aporte del género como una categoría de análisis dentro del feminismo contemporáneo, en cuanto evidencia las asimetrías sociales entre varones y mujeres (Mena-López 2015, 1199-1205). Esto es importante, ya que la Biblia ha sido manipulada y usada a favor de lecturas fundamentalistas y excluyentes.

Lo asumimos desde el feminismo crítico como una reflexión que no es hecha sólo para mujeres y que apela por igual a mujeres y varones preocupados por la justicia, la verdad y la transformación social, y lo haremos reconociendo nuestras limitaciones en el abordaje de un tema tan amplio, rico y complejo.

Quienes hacen uso del género como ideología fundamentan sus juicios y postulados en lecturas bíblicas descontextualizadas. En este sentido, conviene reflexionar sobre el peligro que tienen las lecturas fundamentalistas de la Biblia en nuestros días, no sin antes hacer unas aproximaciones conceptuales al género como ideología.

\section{Que es en sí la ideología de género}

Autores como Junqueira (2017) y Vilà (2016, 75-88) señalan que la «ideología de género» corresponde a una invención vaticana, pero tuvo gran acogida entre sectores conservadores no pertenecientes a la Iglesia Católica Romana, especial- 
mente en la primera década del presente siglo y que ha permitido confluir las más diversas expresiones de clasismo, racismo, machismo, sexismo y xenofobia, y que al parecer se constituye en una estrategia que reconfigura las agendas políticas de los grupos cristianos y sectores más conservadores para combatir los avances sociales en materia de derechos, especialmente sexuales y reproductivos.

\subsection{Origen del concepto}

En respuesta a los debates para la aprobación de los documentos de la Conferencia Internacional sobre la Población en El Cairo, en 1994, y la Conferencia Mundial sobre la Mujer en Beijing el año siguiente, el Vaticano convocó decenas de «expertos» para armar una contraofensiva que reafirmara la doctrina católica y la naturalización de orden sexual.

En paralelo, voces discrepantes provenientes en su mayoría de los mismos sectores conservadores de la Iglesia Católica Romana se iban levantando a lo largo del mundo, como es el caso de Christina Hoff Sommers, académica antifeminista, de la Universidad de Clark, quien en 1994 publicó el libro ¿Quién nos robó el feminismo? (Hoff 1994), que con ayuda de un grupo de reflexión de la derecha estadounidense rebatió el «feminismo de género», señalando que este movimiento, en lugar de buscar la igualdad de derechos para hombres y mujeres, llegó a antagonizar las desigualdades históricas en función del sexo, hablando del patriarcado, la dominación masculina y el sistema sexo-género.

Otra representante importante en contra de los avances sociales, es la periodista y escritora estadounidense Dale O'Leary, miembro del Opus Dei y de la Asociación Médica Católica de Estados Unidos y la Asociación Nacional para la Investigación y Terapia de la Homosexualidad, que promovía la terapia reparativa de la conducta homosexual. Entre los trabajos de O'Leary se encuentra el libro La agenda de género: redefiniendo la igualdad (1997). Este y otros materiales en torno a la defensa de la moralidad y la familia tradicional son difundidos y replicados on-line por medios de comunicación católicos y son tenidos como referentes.

En La Agenda de Género, O’Leary retomó a las feministas del género, acusándolas de marxistas y de promotoras de una «ideología» que le falta al respeto a las diferencias biológicas y llama a la «guerra de los sexos»; además, señala que la idea de la construcción social de los roles de género tiene como objetivo «la abolición de la naturaleza humana» y evitar que la mujer cumpla con su función de cuidadora.

Según la autora, la «agenda de género» tiene por objetivo construir un mundo con menos personas, más placer sexual, sin diferencias entre hombres y mujeres, sin madres a tiempo completo. Para lograr estos objetivos, se busca garantizar:

1. el libre acceso a la anticoncepción y el aborto,

2. promover la homosexualidad, 
3. ofrecer educación sexual a niños y jóvenes para estimular la experimentación sexual,

4. la abolición de los derechos de los padres a educar a sus hijos,

5. establecer la paridad entre hombres y mujeres en el lugar de trabajo, promoviendo la inserción de las mujeres en el mercado laboral, y

6. desacreditar religiones que se oponen a este proyecto.

Como se puede notar, los argumentos de O'Leary siguen siendo el fundamento de los movimientos anti-derechos, quienes constantemente retoman la idea que la agenda de género está promovida por movimientos de feministas radicales, populistas, de liberación sexual, activistas homosexuales, ambientalistas, neomarxistas y deconstructivistas posmodernos; cuyo principal objetivo es dominar las organizaciones internacionales, las universidades y el Estado. La ONU, según Michel Schooyans (2001), ya estaría bajo su dominio, encontrándose a la deriva, bajo el interés de las minorías subversivas que promueven una cultura «anti-familia», «el colonialismo sexual» y «la ideología de la muerte».

En el mismo 1997, monseñor Schooyans, referido anteriormente, publicó el libro L'Évangile face au désordre mondial (1997), con un prefacio escrito por el cardenal Joseph Ratzinger, en ese entonces prefecto de la Congregación para la Doctrina de la Fe y posterior Papa Benedicto XVI. En éste, como en otros textos, el belga hace una fuerte crítica del aborto y el uso de anticonceptivos; así mismo, dedicó un amplio espacio para la denuncia de la «ideología de género». Este es posiblemente, uno de los primeros trabajos -si no el primero- en el que se utilizó la expresión.

En abril de 1998, la expresión «ideología de género» apareció por primera vez en un documento eclesial de la Conferencia Episcopal Peruana (1998). En el texto titulado: La ideología de género: sus peligros y alcances, el arzobispo Oscar Alzamora Revoredo, de la Comisión ad hoc de la mujer y Obispo Auxiliar de Lima, denuncia que la ideología de género promueve que «las diferencias entre el varón y la mujer, fuera de las obvias diferencias anatómicas, no corresponden a una naturaleza». Este obispo se basó, según él mismo establece al inicio del texto, en el informe «La desconstrucción de la mujer» de Dale O'Leary.

Poco después, la expresión «ideología de género» apareció en un documento de la curia romana, con motivo de la publicación del documento Familia, matrimonio $y$ «uniones de hecho», del 26 de julio. En este documento, el Pontificio Consejo para la Familia señala que:

Dentro de un proceso que podría describirse como la progresiva desestructuración cultural y humana de la institución del matrimonio, no se debe subestimar la propagación de una determinada ideología de «género» (Pontificio Consejo para la Familia 2000).

En 2003, bajo el auspicio del Pontificio Consejo para la Familia, se publicó el que podría considerarse el documento más amplio, incisivo y polémico; El lexicón 
de la Familia (Pontificio Consejo para la Familia 2017), sobre términos ambiguos y discutidos sobre familia, vida y cuestiones éticas; documento coordinado por el cardenal colombiano Alfonso López Trujillo, un firme opositor de la teología de la liberación, del uso de preservativos, el matrimonio homosexual y la investigación sobre células madre, entre otros temas. El Lexicón tuvo más dos ediciones, la segunda publicada en el 2004 y la tercera en 2017, en que se cuentan 103 artículos apologéticos en torno al género, la sexualidad, la bioética, preparados por más de 70 autores.

El escrito ¿Qué Quiere Decir género?, de Jutta Burggraf (2001), teóloga alemana y numeraria del Opus Dei, se constituye en el aparato ideológico que hoy en día circula y fundamenta los movimientos en contra de la «ideología de género»; aparato que tiene como matriz el trabajo de Dale O'Leary.

Por último, en 2011, el sacerdote Juan Antonio Montes, de la Acción Familia por un Chile auténtico, cristiano y fuerte, editó un libro en contra la teología eco-feminista. El autor presenta, según su criterio, los principales postulados de la «neo revolución eco-feminista», donde según él, la crítica sobre la relación intrínseca entre la dominación de la naturaleza y de la mujer en la sociedad patriarcal contribuye a la generación de una sociedad andrógina y, en sus palabras, «tales aberraciones sólo pueden darse en la cabeza de pobres extraviadas que, de tanto leer y sofismar, llegaron a esas conclusiones» (Montes 2011, 12). Ante esa aseveración, como diría Ivone Gebara, todavía en pleno siglo XXI, «llegamos al extremo de destruirnos mutuamente, para mantener las jerarquías nefastas que nos esclavizan unos a otros» (Gebara 2017a, 10).

\subsection{Auge actual del debate}

Si bien la «ideología de género», tal y como se señaló, surgió en el ambiente eclesiástico y de los sectores de ultra derecha del catolicismo romano, también es cierto que fue hasta el 2012 que se prendió el debate en la esfera pública.

La iniciativa del movimiento francés Manif Pour Tous (MPT) de frenar los avances en materia de derechos de los sectores LGBTI se constituye en un hito en los procesos de movilización social que se han visto en América y Europa, tal y como lo señala David Paternotter en el libro de memorias del evento Habemus Gender, celebrado en la Université de Bruxelles (2016). Aunque esta iniciativa fue presentada como civil y no religiosa, es importante no perder de vista el protagonismo de los sectores conservadores de la iglesia católica romana a estos respectos, pues uno de los más acérrimos detractores en la década de 1990 a las políticas que favorecían el avance en materia de derechos de las personas LGBTI fue el obispo y psicoanalista francés Tony Anatrella, y resulta significativo que los argumentos, aparentemente civiles, de MPT coincidieron con lo expuesto por el monseñor francés.

Pero, ¿cómo es que los movimientos en contra de la «ideología de género» llegaron a América Latina? Al parecer, los movimientos españoles Hazte Oir y 
CitizenGo $\mathrm{G}^{5}$ y organizaciones con sede en América Latina, como es el caso de la Organización para el Bien Común, o Yunque, como es más conocida, entraron a América Latina con una postura radical en contra del matrimonio igualitario, el aborto y la laicidad del Estado. Estas posturas fueron radicalizadas por movimientos de extrema derecha que han tenido influjo a nivel político, social y religioso.

Los elementos comunes de estas organizaciones son sus agendas, centradas en detener avances sociales en materia de derechos, especialmente sexuales y reproductivos, así como la vinculación de personas de extrema derecha con grandes capitales económicos. Y aunque durante mucho tiempo habían tratado de frenar los avances en esta materia, a través de la oposición al acceso de mujeres a métodos anticonceptivos, a la interrupción del embarazo, la experimentación con células madres y la educación sexual en la escuela, fue hasta el 2012 cuando lograron crear un enemigo que pudiera despertar la indignación de las personas: la corrupción de los niños y niñas para homosexualizarlos, destruyendo de esta manera la familia y cualquier esperanza de continuidad de la especie humana blanca, ya que las mujeres indígenas y negras han sido objeto de esterilización masiva, sin indignación alguna, desde la década de 1950.

No obstante, en Latinoamérica fue necesario esperar hasta el 2016 para que este monstruo hiciera su entrada y aterrorizara a las familias frente a la idea de una estrategia macabra para acabar con la familia y, con ella, la sociedad. En Colombia, ya desde el 2013 el exprocurador general de la Nación, Alejandro Ordoñez, venía adelantando distintas estrategias para frenar el matrimonio igualitario y bloquear cualquier proceso de avance en materia de derechos sexuales y reproductivos.

Para la primera mitad del 2016, el Ministerio de Educación junto con la organización Colombia Diversa y el apoyo de la UNESCO habían preparado una cartilla que orientara a los docentes y directivos docentes en el proceso de evaluación y actualización de manuales de convivencia, para dar cumplimiento a la Sentencia T-478/2015, conocida como la sentencia Sergio Urrego, ${ }^{6}$ en razón al caso que le dio origen. Antes de que circularan las cartillas, a través de las redes sociales se mostraron imágenes de los comics In bed with David \& Jonathan, cuyo autor es el ilustrador belga Tom Bouden (Saad 2016), aseverando que se trataba de partes de la cartilla. Lo interesante es que el escandalo alcanzó tales magnitudes que una joven

Hazte Oir y CitizenGo son dos movimientos que promueven iniciativas contra derechos civiles en España que poco a poco han hecho presencia en Latinoamérica, con estrategias como el bus naranja, que hizo presencia en las principales capitales latinoamericanas protestando en contra de las políticas de identidad de género, cuyo lema era «los niños tienen pene, las niñas tienen vulva, que no te engañen».

6 Sergio Urrego fue un joven que decidió quitarse la vida en razón a las distintas formas de violencia que tuvo que afrontar, en la institución educativa en la que se encontraba cursando su último año de educación media, por su orientación sexual. El suicidio de Sergio Urrego tuvo un importante cubrimiento mediático y seguimiento por las autoridades. 
diputada de Santander terminó haciendo control político a la ministra Parody $^{7}$ por dichas cartillas.

Ángela Hernández, la joven santandereana, del partido de la U, hasta ese momento anónima, empezó a señalar que el Ministerio de Educación Nacional tenía una política de homosexualización. De un momento a otro el debate creció tanto que se empezaron a organizar movimientos de padres de familia para protestar. Hecho que, gracias a las artimañas políticas de algunos sectores, encabezados por el señor Ordoñez, se logró articular con el proceso de refrendación de los Acuerdos de Paz de la Habana, y se denunció que, además del Ministerio de Educación, otras instancias del gobierno estaban infiltradas por el Lobby Gay y que el mismo acuerdo estaba permeado por dicha ideología, echando mano del hecho que los sectores LGBTI fueron reconocidos como víctimas del conflicto armado.

Es así como la diputada Ángela Hernández y el exprocurador general Alejandro Ordoñez terminaron aliados en la organización de marchas a nivel nacional para protestar contra las políticas del Ministerio de Educación y concretamente contra la ministra Parody, de quien se utilizó su conocida orientación sexual lésbica para atacarla. En las marchas, programadas en su mayoría para el 16 de agosto de 2016, se invitaba a protestar contra la ideología de género, contra el presidente y contra el acuerdo de paz. En pocas palabras, se logró capitalizar la indignación ciudadana frente a la desinformación que habían generado algunos sectores de la política, especialmente provenientes del uribismo, ${ }^{8}$ en torno al Acuerdo de la Habana dando como resultado una masiva movilización de los colombianos en distintas ciudades del país.

El protagonismo de las Iglesias Cristianas fue evidente en la organización y difusión de las marchas. No obstante, no fue un espacio meramente de cristianos, sino de todos aquellos que se sentían en desacuerdo con la tal «ideología de género» que se quería imponer en los colegios, así como las personas que apoyaban el No a la refrendación de los acuerdos de paz entre el Gobierno y las FARC.

Con el posterior triunfo del No en las urnas, los sectores cristianos se empoderaron como un sector fuerte electoral, lo que los posicionó como agentes claves en la renegociación de los Acuerdos de la Habana (Alto comisionado para la paz 2016), tanto así que, después del proceso de votación para la refrendación, el presidente tuvo una reunión privada con líderes cristianos, quienes exigían la renuncia de la ministra Parody, el reconocimiento de las iglesias cristianas como agentes sociales en el proceso de paz y la supresión de la ideología de género de los Acuerdos.

Ginna Parody es una abogada y política de Colombia, ministra de educación desde el 2014 hasta el 2016, que tuvo que renunciar a su cargo a raíz del escándalo del sector educativo por las cartillas y más concretamente después del triunfo del no en el plebiscito nacional. Ver <http:// ginaparody.com/web/biografia> [consultado el 25 de enero de 2017].

$8 \quad$ El uribismo se denomina en Colombia al apoyo político que los ciudadanos y algunos sectores políticos le profesan al expresidente Álvaro Uribe Vélez, fundador del partido de la U. 
Podría decirse que los grandes ganadores en el proceso de refrendación de los Acuerdos de La Habana fueron los cristianos, quienes a partir de ese momento empezaron a tener un importante cubrimiento mediático, a tal punto que algunos llegaron a catalogarlos del nuevo botín electoral para el 2018.

Actualmente, el debate en torno a la ideología de género sigue centrando su atención en la agenda de los sectores homosexuales, para imponer una cultura gay. No obstante, junto a ese debate se empezaron a jalonar otros que le son propios ideológicamente a los grupos conservadores: la prohibición de educación sexual en la escuela, la penalización del aborto y la limitación al acceso de métodos anticonceptivos.

Sin embargo, no sólo en Colombia se han presentado estos debates en Brasil, Chile, Costa Rica, México y Perú, y más recientemente en Ecuador; el debate está en furor, con las mismas características de los procesos llevados a cabo en Colombia.

Es importante señalar que los grupos cristianos lograron unir las más diversas agendas de sectores conservadores de iglesias y de la sociedad en general; grupos que ven en la ideología de género converger sus temores en torno a una liberación sexual y a las implicaciones políticas de ésta. Es así como también se puede identificar en el discurso una especie de asociación de los grupos pro derecho a movimientos ideológicos de izquierdas marxistas. No es extraño escuchar de la dictadura «castro chavista» impulsada por los grupos LGBTI.

\section{Falacias discursivas bajo el manto de la ideología de género}

En el anterior recorrido, se puede evidenciar como, aunque el énfasis actual de la llamada ideología de género se ha puesto en la búsqueda de frenar los avances en materia de derechos de civiles de las personas con orientación sexual e identidades de género no hegemónicas, el trasfondo sigue siendo el mismo; controlar los cuerpos, el placer sexual, el derecho de decidir etc. Las luchas de las feministas cristianas no son luchas de consuelo y seguridad emocional (Gebara 2017b). Ellas generan disturbios al orden religioso vigente, invitan al pensamiento y a la generación de nuevas comprensiones de la vida. Ante esta realidad constatamos:

1. El refuerzo de una jerarquía de género que tiene poder y que subvalora la razón como siendo de orden masculina y que además domina lo sagrado;

2. El uso de neologismos del siglo XXI para interpretar textos polémicos sobre la sexualidad en la Biblia;

3. Un volver a los fundamentalismos y exclusivismos religiosos, políticos y económicos (Pereira 2016, 15-26) para mantener el statu quo de la moral cristiana eclesial trasplantada a la familia y a la escuela, las dos instituciones básicas de instrucción;

4. Es un quitar el cuerpo y las emociones porque esto es subversivo y peligroso; 
5. Es un volver a la monocultura y universalismos que esconden nuestros avances en cuanto a la experiencia de las mujeres en razón a su raza, clase, sexo, generación, vida cotidiana, etc. Categorías que han acompañado el análisis de género;

6. Hay un retorno al padre patriarcal, a aquel que valida los límites y alcances del feminismo. Hasta parece que necesitamos de ese reconocimiento para continuar. En la encíclica Amoris Letitia, el Papa Francisco reflexiona sobre la «mujer»y «la ideología de género»: en el parágrafo 54 se inicia afirmando los derechos de la mujer y su importancia en su participación en los espacios públicos, al tiempo que describe las formas del feminismo que parecen ser adecuadas; mientras afirma en el parágrafo 56 que la «ideología de género» niega la reciprocidad natural, sin explicar a qué se refiere con esto;

7. El resurgir de nuevas definiciones de lo que es un hombre y lo que es ser mujer sustentadas en la jerarquía de género y en la heterosexualidad normativa;

8. No hay apertura para discusiones teóricas tales como las diferencias existentes entre teoría e ideología; natural y antinatural, construcciones culturales, reglas, códigos simbólicos e identidades plurales, ni en la encíclica, ni en la iglesia a partir de los desafíos que la contemporaneidad exige.

Ante todo lo anterior, las feministas nos sentimos huérfanas, extrañas, extranjeras del mundo que nos educó. Sentimos indignación, dolor y humillación. La gran paradoja es que mientras unos son humillados, otros son exaltados. Esto es insoportable a la hora de pensar en derechos sociales y bienes comunes.

Es por esto que un desafío ético para una iglesia inclusiva y liberadora en los días actuales debería ser el volver hacia la divinidad que se revela en la vida cotidiana de las y los excluidos. Es decir, volver al principio de la misericordia encarnada y comprometida no solo con el dolor humano, sino también con el retorno de la esperanza de sus seguidores/as y que abrace la diversidad. Esto significa también, recuperar la plenitud de la vida, de lo transcendente, de lo espiritual y sacral de los cuerpos sexuados.

En tal sentido, mientras se continúe pensando binariamente a hombres y mujeres, y el lugar de unos y otros se relacionen con las características biológicas, se continuará perpetuando la desigualdad. De hecho, será imposible pensar un proceso de igualdad entre hombres y mujeres si se mantienen las visiones tradicionales de lo que significa ser hombre y mujer. Es por ello que para las perspectivas queer la identidad no es algo fijo y permanente sino que es transitoria. Más allá de las características biológicas genitales, el lugar en la sociedad es una construcción personal que incluso puede migrar.

Las mujeres no pueden seguir siendo vistas, apreciadas y respetadas en función a la maternidad y de la función de cuidadoras, sino que deben tener la libertad de determinarse sin más limitante que su propia voluntad. De igual manera, el hombre no debe ser medido, por su vigor, fuerza y capacidad de protección, sino 
que debe tener la libertad de autodeterminarse. En tal sentido, la identidad masculina y femenina ya no es una categoría fija, sino que permite tránsitos. Tránsitos que no deben ser sinónimos de desigualdades y sometimientos, ni mucho menos de una moda que desvía la conducta de otros. Es un derecho de ser y existir, es ante todo una apuesta evangélica por el respeto, el amor y la posibilidad de vivir en una tierra armónica y feliz, libre de preconceptos.

\section{Referencias bibliográficas}

Alto comisionado para la Paz. 2016. Acuerdo final para la terminación del conflicto y la construcción de una paz estable y duradera. Bogotá. Disponible en http://www.altocomisionadoparalapaz.gov.co/procesos-y-conversaciones/Documentos\%20compartidos/2411-2016NuevoAcuerdoFinal.pdf [Consultado el 24 de enero de 2017].

Aguilar, Marcio Mucedula. 2007. «A construção das hierarquias sociais: classe, raça, gênero e etnicidade». Cadernos de Pesquisa do CDHIS (36/37): 83-88. Disponible en http://www. seer.ufu.br/index.php/cdhis/article/view/1204

Burggraf, Jutta. 2001. ¿Qué quiere decir género? Un nuevo modo de hablar. San José, Costa Rica: PROMESA.

Castellanos, Gabriela. 2007. Sexo, género y feminismo tres categorías en pugna. Disponible en https://es.slideshare.net/pa1234/6-sexo-genero-y-feminismo-tres-categorias-en-pugna-2086684 [Consultado el 13 de enero de 2017].

Conferencia Episcopal Peruana. 1998. La ideología de género, sus peligros y alcances. Lima: ACI Prensa. Disponible em https://www.aciprensa.com/controversias/genero.htm [Consultado el 12 de enero de 2017].

Corte Constitucional de Colombia. 2015. Sentencia T-478/15. Disponible en http://www.corteconstitucional.gov.co/relatoria/2015/t-478-15.htm [Consultado el 20 de noviembre de 2017].

Gebara, Ivone. 2017a. Mulheres, religião e poder. Ensaios feministas. São Paulo: Terceira Via Edições.

Gebara, Ivone. 2017b. Ecofeminismo: Desafios para pensar a teologia. São Paulo: Terceira Via edições.

Hoff, Christina. 1994. Who Stole Feminism? How Women Have Betrayed Women. Nueva York: Touchstone.

Human Rights Watch. 2014. Informe Mundial Colombia. Disponible en https://www.hrw.org/ es/world-report/2014/country-chapters/260120 [Consultado el 13 de enero de 2017].

Junqueira, Rogerio. 2017. «Ideologia de gênero: um dispositivo retórico de uma ofensiva antifeminista». En Gênero e sexualidades: entre invenções e desarticulações, organizado por Alfrâncio F. Dias, Elza F. Santos y Maria Helena S. Cruz. Aracaju: Editora IFS.

Lings, Renato. 2011. Biblia y Homosexualidad ¿Se equivocaron los traductores? San José, Costa Rica: Editorial Sebila, Universidad Bíblica Latinoamericana.

Mena-López, Maricel. 2015. «Género y Estudios de la Religión». Horizonte, 13 (39): 11991205. DOI: https://doi.org/10.5752/P.2175-5841.2015v13n39p1199

Montes, Juan Antonio. 2011. Una revolución enquistada en la Iglesia, intenta destruir la civilización y la moral cristiana: Desde la Teología de la Liberación a la Teología eco-feminista. Santiago de Chile: Acción Familia. Disponible en http://www.tfp.org/books/Desde_ la_Teologia_de_la_Liberacion_a_la_Teologia_Eco-Feminista.pdf [Consultado el 13 de enero de 2017]. 
O'Leary, Dale. 1997. The Gender Approach: Redefining Equality. Lafayette, LA: Huntington House Publishers.

Paternotter, David 2016. «Habemus Gender! Autopsie d'une obsession vaticane». En Habemus Gender! Deconstruction d'une riposte religieuse, organizado por Sophie van der Dussen, David Paternotte y Valérie Piette. Bruselas: Éditions de l'Université de Bruxelles, 7-22.

Pereira, Nancy Cardoso. 2016. «Educação e diversidade em tempos de fundamentalismos». En Género e diversidade: debatendo identidades, organizado por Marcia Alves da Silva. 1. ${ }^{2}$ ed. São Paulo: Perse.

Pontificia Comisión Bíblica. (1993) 2005. La Interpretación de la Biblia en la Iglesia. 7.a ed. Madrid: Ediciones PPC. Disponible en http://www.servicioskoinonia.org/biblioteca/ biblica/InterpretacionBibliaIglesia1993.pdf

Pontificio Consejo para la Familia. 2017. Lexicón, términos ambiguos y discutidos sobre familia, vida y cuestiones éticas. 3. ${ }^{a}$ ed. Madrid: Ed. Palabra.

Pontificio Consejo para la Familia. 2000. Familia, matrimonio y «uniones de hecho». Roma: Pontificio Consejo para la Familia. Disponible en http://www.vatican.va/roman_curia/ pontifical_councils/family/documents/rc_pc_family_doc_20001109_de-facto-unions_ sp.html [Consultado el 12 de noviembre de 2017].

Ramírez, Fidel, y Maricel Mena-López. 2014. «Aportes desde la perspectiva queer para la reforma curricular de la escuela en busca de la equidad de género». Ciudad Paz-ando 7(1): 106-124. DOI: https://doi.org/10.14483/udistrital.jour.cpaz.2014.1.a06

Saad, Said Sarquis. 2016. «La misteriosa cartilla que presumiblemente ronda en las escuelas». El Heraldo, de 7 de agosto de 2016. Disponible en https://www.elheraldo.co/local/ la-misteriosa-cartilla-que-presuntamente-ronda-por-las-escuelas-276827 [Consultado el 13 de enero de 2017].

Schooyans, Michel. 1997. L'Évangile face au désordre mondial. Paris: Fayard.

Schooyans, Michel. 2001. The Hidden Face of the United Nations. St. Louis, MO: Central Bureau, CCVA.

Scott, Joan. 1990. El género: una categoría útil para el análisis histórico. En Historia y género: Las mujeres en la Europa Moderna y Contemporánea, organizado por James Amelang y Mary Nash. Valencia: Ediciones Alfons el Magnanim.

Vilà, Enric. 2016. «La 'ideologia de género': la caza vaticana a un fantasma». Iglesia viva: Revista de Pensamiento Cristiano 267: 75-88.

Wirherup, Ronald, D. 2009. Fundamentalismo Bíblico. Collegeville, MN: Liturgical Press.

Maricel Mena-López. Docente de la Universidad Santo Tomás, Bogotá. Doctora en Ciencias de la Religión, Biblista. Investigadora en temas y problemas relacionados con género, raza/etnia, clase, interculturalidad y estudios culturales.

Correo electrónico: maricelmena@usantotomas.edu.co

Fidel Mauricio Ramírez Aristizábal. Docente de la Universidad Santo Tomás, Bogotá. Doctor en Educación en la línea de Derechos Humanos y Ciudadanías. Investigador en temas y problemas sociales relacionados con inclusión educativa de estudiantes sexualmente diversos.

Correo electrónico: fidelramirez@usantotomas.edu.co

Artículo recibido el 6 de deciembre de 2017 y aceptado para publicación el 6 de febrero de 2018. 